2018-01-01

Local food in China: a viable destination attraction

Chen, Q

http://hdl.handle.net/10026.1/10697

10.1108/BFJ-03-2017-0135

British Food Journal

Emerald

All content in PEARL is protected by copyright law. Author manuscripts are made available in accordance with publisher policies. Please cite only the published version using the details provided on the item record or document. In the absence of an open licence (e.g. Creative Commons), permissions for further reuse of content should be sought from the publisher or author. 


\title{
Local food in China: a viable destination attraction
}

\begin{abstract}
Purpose

The subject of food has been well researched by academics, and is often employed by tourism destination practitioners. However, a review of relevant literature indicates that there is a lack of research reported and written in English on the importance of food in Chinese local regional development. This study, by examining the food-related motivation, involvement, satisfaction, and behavioural intentions of Chinese domestic tourists, aims to assess the potential of local food to act as a destination attraction, and contribute to the development of local regions in China.
\end{abstract}

\section{Design/methodology/approach}

Data was collected using interviewer-completed questionnaire from a sample of 1353 domestic tourists at eight destinations geographically spread or in one region in China.

\section{Findings}

The results reveal three types of food-related behaviour [which are described and evaluated below]. While gender is seen to be significant, other demographical factors such as ages and educational levels do not appear to influence the level of interests and involvement in local food for Chinese domestic tourists.

\section{Originality/value}

This study is a contribution towards assessing the potential for using local food as a tool to develop local regions in China, and to obtain a better understanding of the market segmentation of Chinese local food tourists. It assists in identifying potential food tourists towards whom marketing should be addressed. 


\section{Introduction}

The growing popularity of food with tourists means that food is increasingly recognised by destinations as contributing towards the development of a destination's economy and culture (Horng and Tsai, 2012). As a unique destination attraction, it is growingly acknowledged as a useful tool for assisting in the marketing of destination distinctiveness (Björk et al., 2016). Due to the widely acknowledged importance of food in tourism, a worldwide research interest from academics and researchers is witnessed. However, some authors (e.g. McKercher et al., 2008) question whether or not food has the real potential to be used as a development tool for destinations to attract tourists.

Mainland China, with a wide range of food resources and a profound food culture, enjoys a well-acknowledged reputation as a food paradise ( $\mathrm{Du}, 2012)$. Food plays a significant role in Chinese life and in all segments of Chinese society (Simmons, 1991). However, a review of relevant literature sources in food and tourism, Huang (2009) reveals that few studies written in English are associated with the context of Mainland China. In a review of Chinese literature sources concerning the role of food as a destination attraction, Chen and Huang (2016) comment that most Chinese studies focus on the regional development of food in a specific destination without really attempting to examine the wider context of China. They also comment that most of research is conducted from the supply side with no empirical data available from the demand side.

Against the above background, this study, aims to assess the potential of Chinese local food to act, from the tourists' perspective, as a destination attraction and thus aid the development of local regions in China. More specifically, this study examines and categorises the domestic tourists in relation to their food-related travel motivation, and assesses the effect of their motivation on food involvement, food satisfaction, and food-related behavioural intentions (Björk and Kauppinen-Raisanen, 2016; López-Guzmán et al., 2017; Robinson and Getz, 2014). In addition, the potential influences of demographical factors on tourist food-related behaviour were also assessed in the study. 
This study, by using the English language, contributes to the understanding of the relationship between food and the development of local regions in China. Instead of focusing on one specific destination, this study considers geographical areas of China; hence, it contributes to understanding of food tourism phenomenon from the view of wider context of China. Its identification of the possible market segments of Chinese local food tourists, it contributes to targets of focused marketing activities.

\section{Literature Review}

\section{Food Tourism}

Food has always been a fundamental and ubiquitous part of tourists' experience regardless of any differentiating criteria (Henderson, 2009; Tikkanen, 2007). Within the settings of tourism, food is more than a form of substance (Mitchell and Hall, 2003). According to Frochot (2003), the consumption of food allows people to achieve most of their travel desires in relation to enjoyment, relaxation, status, education and lifestyle. As a tool for expressing history, culture, and appreciation, food assists tourists in fully experiencing the symbolic, social and entertainment aspects of the destination through the lens of travel (Hall, Sharples, Mitchell, Macionis \& Cambourne, 2003). Therefore, food is growingly recognised as playing an important role in tourists' decision-making process for holiday destinations (Boniface, 2003; Cohen and Avieli, 2004). Food and tourism are closely interrelated (Mason and Paggiaro, 2012; Sánchez-Cañizares and López-Guzmán, 2012).

Although no standard system exists for evaluating the relationship between food and tourism, the interrelationship can be understood through the role of food as an attraction, a product component, a cultural phenomenon, and a contributor to economic development in tourism (Chen and Huang, 2016). Firstly, food is a tourist attraction that is available all year-round. It can be presented in various forms, such as fresh seafood in seaside resorts, peculiar ethnic cuisines of exotic peoples, and renowned restaurants in luxurious hotels (Cohen and Avieli, 2004; Henderson, 2009). Secondly, food is a basic and crucial element of the tourism product (Henderson, 2009; Tikkanen, 2007). Food can either add value to a core tourism product or it can be viewed as a stand-alone tourism product for tourists who intentionally search for food activities. Thirdly, food is a great way to acquire cultural capital (Sims, 2009). It is a cultural 
encounter when tourists have authentic local experiences like drinking local wine or eating local food. Lastly, food contributes to increasing tourist spending, generating revenues, and increasing local employment (Quan and Wang, 2004). Food can also create substantial economic opportunities for local businesses (Henderson, 2009)

\section{Profiling Food Tourists}

The tourist market is not a homogenous set due to the various changes of tourism patterns (Smith and Costello, 2009). Robinson and Getz (2014) divide current food tourism literature into two thematic streams: supply-side and demand-side; one thing in common in the demandside studies is that they take the perspective of the potential and/or observed food tourists and attempt to segment the tourists.

Boyne et al. (2003) and McKercher et al. (2008) suggest that the food tourist market could be segmented based upon the importance of food in the travel motivations of tourists. Smith and Costello (2009) argue that segmenting tourists through motivations and understanding the characteristics of their food-related behaviours should assist marketers in recognising the strengths and opportunities of each market segment. Specifically, there is a continuum of tourists' motivations according to the importance level, which food plays in their travel decision-making process. With the movement through the continuum of tourists, the role of food is playing a progressively descending role. Based on the role of food in the travel motivations, the food tourist market can be segmented into three different types (McKercher et al., 2008). Hjalager (2004) categorise food tourists from a lifestyle perspective into four groups including experimental, existential, recreational, and diversionary tourists. Mitchell and Hall (2003) advocate four types of food tourists including gastronomes, indigenous foodie, tourist foodie, and familiar foods based on tourists' interest and involvement with local food.

Although there are studies about segmenting food tourists, no studies, in either the English or the Chinese language consider the categorisation of Chinese food tourists. The huge potential of the food tourism market in China, and the lack of relevant research in this aspect, make it apparent that there is an urgent need for research to fully understand the market segment of Chinese tourists seeking local foods in China. Previous segmentation literatures inform the empirical design of our study of tourist motivation as well as their food-related behaviours (i.e food involvement, satisfaction, and behavioural intentions).

\section{Chinese Local Food and related tourism research}


Mainland China has a vast and varied landscape, which has produced rich and diverse food resources, as well as a unique, adaptable, and profound food culture (Chang, 1977). Chinese cuisine has created a global reputation and popularity through nearly 5,000 years of development (Du and $\mathrm{Li}, 2010)$. History witnessed the development of a variety of cooking forms and styles, which were gradually shaped into 'Eight Major Schools of Cuisine' (Lu, Chuan, Yue, Min, Su, Zhe, Xiang, and Hui) based on different geographical regions (Du and Li, 2010; Hu, 2006). Chinese people are particularly passionate and serious about food and eating (Chang et al., 2010; Guan and Jones, 2014); this is signified by the traditional Chinese sayings 'To the people, food is heaven' and 'Heaven also loves the man who eats well'.

Previous studies (Chang et al., 2010; Pearce et al., 2013) observe that due to the influences of globalisation, it is becoming fashionable and desirable for Chinese people to consume food that is different in taste, culture and quality and thus broaden their culinary experiences. Some authors (Du, 2012; Gong, 2011) report that foodies are emerging in China with more and more people showing interest in food during their travel. Qi et al. (2009) and Sun and Xie (2014) recognise that the traditional forms and contents of tourism can no longer meet Chinese people's needs because of their improving living standards. However, a review of food promotion by destination management organisations in China, Huang (2009) argues that it remains unexplored as to what extent local food contributes towards tourism development in Chinese regions.

In order to evaluate the value of food as a destination attraction in Mainland China, a review of the existing food and tourism studies was conducted. The first Chinese academic research on food and tourism dates back in 1986, in which Gu and Gao (1986) investigate the catering industry in the tourism destination of Hangzhou, and propose food and tourism are closely related. However, between 1986 and 2003, very few Chinese academic studies were published on food and tourism. After 2003, food tourism as a research theme started to attract the attention of Chinese researchers again, and a number of studies emerged. This phenomenon is attributed to emerging food tourism research (Boniface, 2003; Hall et al., 2003; Long, 2004) outside China. Although few English publications are associated with the research context of Mainland China, the literature of Western food tourism contributed greatly to the research of Chinese food tourism. 
In comparison to the Western food tourism research, food tourism in China is a still a new research area. In particular, a thorough review of the food tourism literature in China (Chen and Huang, 2016) reveals that a dominant research focus is on assessing the importance of food in developing the local tourism of a single region or destination in China. In addition, most of these studies are conducted from the supply side with very few empirical studies from tourists' perspective. No studies attempt to investigate the importance of food from the wider geographical areas of China (Yu et al., 2009). Consequently, there is a great need for research into evaluating, from the tourists' perspective, the benefits of developing local food, within the context of all of Mainland China.

\section{Methodology}

This study developed a quantitative survey questionnaire to assess the development potential of food towards local tourism in China; it did this by identifying possible market segments of Chinese food tourists. Specifically, the first section assessed the importance of food as a travel motive in the tourists' pre-travel stage (McKercher et al., 2008; Kim et al., 2010). The second section examined tourists' involvement with local food and food-related activities (Sparks, 2007), and the third section evaluated tourists' satisfaction (Mason and Paggiaro, 2012), as well as tourists' food-related behavioural intentions (Björk and Kauppinen-Räisänen, 2014). The final section dealt with questions seeking the socio-demographic profile of respondents.

As the target population of the study were Chinese domestic adult tourists, the questionnaire was translated into Chinese using a back translation approach described by Brislin (1976) to ensure the meaning of translation was consistent. A pilot study was administered to domestic tourists at a tourist destination (Yangzhou) in China in early April 2014. It aimed to check wording, sequencing, layout of questionnaire, and to estimate response rate and interview time. Based on results of the pilot study, the questionnaire was finalised for the main survey.

Concerning data collection, due to China's vast, diverse landscape and widely scattered domestic tourists, survey destinations were selected using judgement sampling to represent the whole context of Mainland China. In particular, 'Eight Major Schools of Cuisine' as a criterion 
was derived from literature review to identify eight different survey destinations (i.e. Changsha, Chengdu, Guangzhou, Nanjing, Hangzhou, Hefei, Qingdao and Xiamen) to represent the typical geographic characteristics of Chinese culinary culture. At each survey destination, the questionnaire was administrated at the departure lounges of coach stations, train stations, and airports using the next-to-pass non-probability sampling technique recommended by the Tourism and Recreation Research Unit (1983) to secure randomness. Precisely, when one questionnaire has been completed, the next person to pass is approached and screened with the identified criteria to see if it is applicable to continue the survey. With the help of pre-trained research assistants, 1353 valid responses were collected during the main survey between May and June in 2014.

The collected data were analysed using the SPSS 21.0 software. Several analysis procedures were adopted: (1) descriptive statistics were performed to obtain the profile of the total sample and their preference of Chinese regional food; (2) a cluster analysis using a non-hierarchical $\mathrm{K}$-means clustering algorithm was implemented. The K-means procedure was used because it is more suitable for the sample size (larger than 200), and it is less vulnerable to data outliers, the inclusion of irrelevant variables, and the usage of distance measure (Hair et al., 2005). Oneway ANOVA was performed to determine the statistical significance of the differences between clusters; (3) independent t-tests were conducted to test for differences of tourists' food-related behaviours at different travel stages based on gender, and one-way ANOVA were run based on age and educational level.

\section{Results}

Regarding the profile of the respondents, this study gained a higher proportion of female population with $716(52.9 \%)$ female respondents, and 637 (47.1\%) male respondents. With respect to the age distribution, around $89.7 \%$ of the respondents were aged less than 46 years, and $10.3 \%$ were aged above 45 years. The sample group was characterised as being well educated, noting $86.6 \%$ of the respondents had at least an undergraduate degree.

\section{Segmentation of Chinese Domestic Food Tourists}


For evaluating the potential of food in developing local regions in China through examining tourists' food-related behaviours, this study carried out a cluster analysis to provide a more accurate reflection of the potential food tourist market. This study attempted to categorise Chinese domestic tourists based on the six statements measuring the importance of food in affecting tourists' travel motivations. In order to determine the optimum cluster solution, various cluster solutions were tabulated. However, the results revealed that the three-cluster solution has the clearest distinguishable tourist segments with no extreme outliers.

\section{Insert Table 1}

According to Table 1, the first cluster, labelled as disinterested food tourist is the smallest group, taking up only $11.5 \%(n=156)$ of the total sample. The tourists in this cluster indicated the lowest mean scores on all six statements. With an overall mean score of the six statements $(M=2.96)$ below the mid-point of the 7-point Likert scale, this cluster represents tourists who are likely to take food only as part of daily practices before travel. They do not perceive food as an important factor influencing their travel motivations or destination choice.

The second cluster, named as accidental food tourist, represents $42.8 \%(n=579)$ of the sample. This group perceived food as an important motive for their travel $(M=4.66>4)$; however, they did not view food of extreme importance as a motive. In particular, this cluster represents those who are not likely to take food as a primary motive prior to travel with indication of their average rating on the statement evaluating whether food can be a primary motivator $(\mathrm{M}=3.98<4)$.

The third cluster, as the largest segment of the sample, comprising $45.7 \%(n=618)$ of the total. This group expressed the most favourable opinions for the six statements highlighting the significance of food perceived by tourists in their travel motivations. This cluster was named committed food tourist consisting of tourists who view food as a highly significant, and maybe even as a primary motive prior to travel. 
Multi-variate analysis was conducted in order to check if significant differences exist between the three clusters regarding the importance that food plays in their travel motivation. The analysis with the additional post-hoc Scheffe tests both confirmed that significant differences exist between the three clusters at $\mathrm{p}<0.001$, indicating the categorisation of the three clusters is appropriate in the study.

For further testing for significant differences across different clusters in terms of tourists' food involvement, food satisfaction, and food-related behavioural intentions, one-way analysis of variance (ANOVA) tests were employed, respectively. In accordance with the significant differences shown among the three clusters in tourists' food-related motivation, the results revealed the three clusters also differ significantly $(\mathrm{p}<0.001)$ in terms of their involvement with local food and food-related activities, satisfaction with the local food experience, and their food-related behavioural intentions. More specifically, committed food tourists, who perceive the most importance of food prior to travel, have indicated the highest level of food involvement, food satisfaction, and food-related behavioural intentions, whereas the disinterested food tourists who express the most negative views before travel indicated the lowest ratings.

The results further strengthen and validate the point of three different clusters of food tourists in China. However, it is worth noting that disinterested food tourists, who did not realise much importance of food prior to travel, nonetheless indicated much higher levels of ratings in their actual involvement with food. Similarly, even though the disinterested food tourists has indicated the lowest ratings on the levels of food satisfaction and food-related behavioural intentions, their average ratings were still all over the mid-point of the rating scale. In other words, the disinterested food tourists have also expressed a fairly high level of food satisfaction, and food-related behavioural intentions. The actual differences on the rating of food involvement, food satisfaction, food-related behavioural intentions among the three groups are not very large. 


\section{Potential Impacts of Tourists' Socio-demographic Profiles}

Personal characteristics, including socio-demographic variables, have been shown to influence tourists' behaviours and food consumption (Kim et al., 2009; Kim et al., 2013). This study thus continued to investigate whether the Chinese domestic tourists' socio-demographic profiles have potential impacts on their food-related behaviours throughout different travel stages. Specifically, to conduct the tests, it created the composite variables of tourists' food-related motivation, food involvement, food satisfaction, and food-related behavioural intentions through calculating the mean scores of its related statements individually.

\section{Insert Table 2}

The independent t-test results from Table 2 confirmed that there were significant differences between males and females in term of their food-related behaviours across all travel stages. More specifically, with the mean scores for females being higher than those for males, females in China, as opposed to their male counterparts, view food as a more important motive prior to travel, showing higher interest and involvement with local food during travel, revealing higher satisfaction with local food experience post to travel, and indicating higher food-related behavioural intentions. One-way ANOVA tests were conducted to explore the impact of age, and educational level on tourists' food-related behaviours throughout their travel. With the conduct of Scheffe post-hoc comparison, no statistically significant differences were detected among different age groups. Moreover, no significant differences were found among the different levels of educational groups regarding tourists' motivation, involvement, satisfaction, and behavioural intentions in relation to food.

\section{Discussion}

The gender profile of the respondents appears to be contradictory to the gender distribution of the general population in China (males account for $51.27 \%$, while female account for $48.73 \%$ of the population) according to the statistics of China's latest national population census (6th) (National Bureau of Statistics of China [NBS], 2011). However, the result is understandable in conjunction with the food tourism study by Robinson and Getz (2014) in Australia, in which 
the gender imbalance was accounted for the fact that females were more likely to respond to food-related surveys. The result is reflective of the age composition of the broader Chinese population from the Population Census (NBS, 2011). Additionally, the sample group is characterised as being well educated, which might be explained by the impacts of the higher education expansion in China ( $\mathrm{Li}$ et al., 2014). This result concurs with the high educational profile of respondents from previous food-related studies (Getz and Robinson, 2014; Kim et al., 2009), which commonly suggested that most tourists who are interested in food and wine experiences are well educated.

This categorisation supported previous studies (McKercher et al., 2008; Björk and KauppinenRäisänen, 2016), which indicated that the tourist market can be segmented into three parts based on the importance of food as a motive perceived by tourists prior to travel. However, despite the differences shown among the three groups, the results firstly reflected the widely acknowledged significance of local food involvement by Chinese domestic tourists, which proved the value and appeal of local food resources and food-related activities in China.

Food is a physical necessity essential to satisfy the needs of the tourists, as well as an attraction that deliver pleasure and entertainment to tourists that generates emotions and experience while on holidays (Horng and Tsai, 2012; Sánchez-Cañizares and López-Guzmán, 2012). The intake of local cuisine is critical for Chinese tourists during their travel (Chang et al., 2011; Guan and Jones, 2014). Whilst travelling Chinese tourists tend to search for novelty, variety and distinctive features (Chang et al., 2011).

It is worth noting when Chinese tourists were at destinations outside the sphere of influence of Chinese food they showed an interest in trying local food, however some of them expressed the view that Chinese food was still their dominant preference at that destination (Chang et al., 2011). Nevertheless, this study accords with previous research by Guan and Jones (2014), in the context of domestic travel that the distinctiveness of the local food experience is critical to Chinese tourists. This may be because Chinese cuisine is well known for its diversity and variation that different schools of cuisines based on different geographical regions enjoy different characteristics ( $\mathrm{Du}$ and $\mathrm{Li}, 2010, \mathrm{Hu}, 2006$ ), domestic tourists can still acquire certain 
aspects of familiarity and palatability from these cuisines under the Chinese culture. Therefore, the high level of involvement with the local food that the domestic tourists have shown in this study is understandable.

Furthermore, this study also showed a high rating on obtaining satisfaction from local food experience by Chinese domestic tourists. Concurring with previous studies (López-Guzmán et al., 2014; Nield et al., 2000), the results proved that local food in China is a significant contributor towards providing satisfaction to tourists' travel. Food is an enjoyable activity that has the ability to satisfy tourists' physiological needs as well as psychological needs (Kivela and Crotts, 2006; Ignatov and Smith, 2006).

In addition, the results indicated that the tourists' had positive intentions to purchase local food products as souvenirs, to know more about food culture and knowledge, and to share and recommend their food experience when they finished travelling. The findings overall enhance the role of local food as a significant contributor to domestic tourists' travel in China. More precisely, the wide popularity of local food products as preferred souvenir products, acknowledged the value that tourists have for local food products (Björk and KauppinenRäisänen, 2014). The willingness that Mainland Chinese tourists' have for 'experience sharing' has revealed a great potential for promoting local foods at tourism destinations through tourists' positive 'word of mouth', and further highlighted the growing popularity and promotional power of social media with tourists in China.

In relation to influence of socio-demographic factors, the research support previous studies (Ignatov and Smith, 2006; Kim et al., 2009, Robinson and Getz, 2014) that females, rather than males, have the higher interests in food tourism. Specifically, female respondents expressed higher intentions in tasting local food prior to travelling (Kim et al., 2009), revealed higher levels of involvement and excitement with local food and wine activities during travel (Ignatov and Smith, 2006), and expressed higher intentions to purchase food-related souvenirs post travelling (Chen and Huang, 2016).

Nevertheless, the results differ from the findings of Ryu and Han (2010), which noted that prior to travel male tourists showed more interest than females to experience local food because 
females were less willing to take the potential risks carried by the unfamiliarity with local food. However, once female tourists had positive experiences with local food at any travel destination, they were then more willing than males to engage with local food. Therefore, a possible explanation for the above discrepancy with the current study could be attributed to the domestic research context of China. Domestic tourists might not perceive the same levels of 'risk of uncertainty' despite the fact that food across China enjoys locality and varying characteristics.

The results corroborated with previous studies (Björk and Kauppinen-Räisänen, 2014; Sánchez-Cañizares and López-Guzmán, 2012) that age was also not an influential factor affecting tourists' food involvement, and tourists' food satisfaction (López-Guzmán et al., 2014). The results also supported the view that tourists' food involvement was not affected by educational levels (Kim et al., 2013; McKercher et al., 2008), and tourists' food satisfaction was not linked to their educational levels (López-Guzmán et al., 2014; Nield et al., 2000). The findings reflected the appeal of food to the wide domestic tourist community in China, and indicated the potential of successfully developing tourism based upon local foods in China.

\section{Conclusion}

Chinese food and cuisine play an essential role in Chinese people's everyday life and China has many food and tourism resources. Based on the tourists' perceived importance of food as a motive prior to travel, a cluster analysis segmented the tourist market into three different types (disinterested food tourists, accidental food tourists, and committed food tourists). Through examining differences among the three clusters in terms of their food-related behaviours (food involvement, food satisfaction, and food-related behavioural intentions) throughout different travel stages, the results successfully addressed the value and benefits of developing food as a tourism attraction across destinations in China

It is worthwhile to note that in comparison to the big differences that exist in terms of tourists' perceived significance of food prior to travel among the three clusters, the differences among the ratings in terms of their food involvement during travel, food satisfaction and food-related 
behavioural intentions post to travel actually decreased. The results enhanced the wide appeal of food and food-related activities to domestic Chinese tourists during their travels. Food proved to be playing a vital role in enhancing the domestic tourists' experience in China.

Among all the demographical factors, only gender was an influential factor, indicating that female domestic tourists in China attach more significance to the role of food throughout their travel experience. Other demographic factors, including age and educational levels, showed no significant influence on tourists' food-related behaviours. Chinese domestic tourists, regardless of age and educational level, are very likely to be fascinated and well engaged with local food and food-related activities when they travel.

This study addresses clear contributions for the wider food and tourism industry. Firstly, this study confirms that food is an importance factor influencing tourists' choice of destination (Boniface, 2003; McKercher et al., 2008), as well as contributing to tourist behaviour and travel satisfaction (Boniface, 2003; Björk and Kauppinen-Räisänen, 2016). Secondly, this study reveals three types of food-related behaviours, and Swanson and Timothy (2012) emphasise that studies that reveal typologies contribute valuable insight for tourism and hospitality businesses and regional development. By using a large-scale sample to examine food experience and food-related behaviours of Chinese domestic tourists, this study contributes to a better understanding of the market segment of Chinese tourists, as well as assessing the potential of developing food as a destination attraction in China.

Based on the outcomes of this study we offer the following recommendations to destinations that intend to promote themselves through food:

1. The research verifies the development value of food as a destination attraction for destination marketers across China and demonstrates three food-related travel behaviours. Therefore, Chinese destinations should fine-tune their marketing strategies based on the food-related segmentation of the tourists. López-Guzmán et al. (2017) argue that recognition of the differences in food-related travel behaviour will enable 
destinations to tailor their marketing tactics. The development of interesting and attractive food routes, when combined with related food stories, famous people and good restaurants could be used to develop tailor-made travel products (Wang, 2011).

2. The three clusters in this study have shown their interests and engagement with the local food and food-related activities. Marketers need to review the mix of food and food-related activities provided at destinations (Croce and Perri, 2010). For sustaining tourists' interests, marketers should pay attention to monitoring the quality of food products and services provided, as well as developing various novel and distinctive food-related activities (Huang, 2009). They need to appreciate the food resources of the places they are promoting, while keeping up to date with the particular demands of the diverse tourist markets, as well as working on improving standards (Henderson, 2009).

3. The study reveals that the committed food tourists group, with uplifted levels of satisfaction and behavioural intentions, represents a significant group of opinion leaders. Destination marketers should focus their marketing efforts on to this group, as committed food tourists are likely to generate more revenue to the local economy and engage in positive word of mouth promotion of their destination (Chang et al., 2010; Pearce et al., 2013). Chinese social media such as Dazhongdianpin and also Mafengwo could be used to identify such group of tourists as these are two popular social media sites used by Chinese tourists to express their views of their travel experience (Bai, 2015)

4. The results show that females are more likely than males to be part of this committed food tourist group, which is consistent with previous studies (e.g. Ignatov and Smith, 2006; Robinson and Getz, 2014). Marketers might want to target their advertising more towards female tourists. Creating unique dining environments, and delivering the local culture through restaurant decoration, tableware, services, or flavour characteristics could be considered when food venues design their augmented service offering (Wu, 2010). 
The limitations of this study need to be considered when it is used to provide direction for future research. Some of the possible influential factors of tourists' food-related behaviours and experience, such as food-related personality traits, food knowledge, and previous experience need to be explored in further depth. Future research should attempt to provide a more complete examination into tourists' food-related behaviours, and investigate whether significant differences exist between the different segmentations. Furthermore, the current research only identified the domestic tourists as the research targets, which might fail to provide a more complete review on the importance of developing food as a destination attraction in China. Future study should carry out an investigation into the tourists' food experience in China with specific examination of international tourists' food experience in China.

\section{References}

Bai, H. (2015), “An examination of customers' adoption of restaurant search mobile applications", Doctoral dissertation, Auckland University of Technology.

Björk, P. and Kauppinen-Räisänen, H. (2014), "Exploring the multi-dimensionality of travellers' culinary-gastronomic experiences", Current Issues in Tourism, [Online First].

Björk, P. and Kauppinen-Räisänen, H. (2016), "Local food: a source for destination attraction", International Journal of Contemporary Hospitality Management, Vol. 28 No.1, pp. 177-194.

Boniface, P. (2003), Tasting tourism: travelling for food and drink, Ashgate Publishing, Burlington.

Brislin, R.W. (1976), "Comparative research methodology: cross-cultural studies", International Journal of Psychology, Vol. 11 No. 3, pp. 215-229.

Chang, K. C. (1977), Food in Chinese culture, Yale University Press, New Haven (CT).

Chang, R. C. Y., Kivela, J. and Mak, A.H.N. (2010), "Food preferences of Chinese tourists", Annals of Tourism Research, Vol. 37 No. 4, pp. 989-1011. 
Chang, R.C.Y., Kivela, J. and Mak, A. H. N. (2011), "Attributes that influence the evaluation of travel dining experience: When East meets West", Tourism Management, Vol. 32 No. 2, pp. 307-316.

Chen, Q. and Huang, R. (2016). "Understanding the importance of food tourism to Chongqing, China", Journal of Vacation Marketing, Vol.22 No.1, pp. 42-54.

China Cuisine Association (CCAS) (2015), "Chinese food consumption survey in 2014", from: http://www.ccas.com.cn/Article/HTML/107208_3.html (Accessed March 3, 2016).

Cohen, E. and Avieli, N. (2004), "Food in tourism: Attraction and impediment", Annals of Tourism Research, Vol.31 No.4, pp.755-778.

Croce, E. and Perri, G. (2010), Food and wine tourism: Integrating food, travel and territory, CABI.

Du, F. X. and Li, X.Q. (2010), Chinese culinary culture, China Travel \& Tourism Press, Beijing.

Du,Y. (2012), 'A bite of China' brings along the heat of food tourism. Hangzhou Daily. from: http://fashion.ifeng.com/travel/roll/detail_2012_06/08/15152455_0.shtml (Accessed October 3, 2015).

Gong, Y. (2011), "Using the love of food to develop tourism value", China Business \& Trade, Vol. 09, pp.160-161.

Guan, J. and Jones, D. L. (2014), "The contribution of local cuisine to destination attractiveness: an analysis involving Chinese tourists' heterogeneous preferences", Asia Pacific Journal of Tourism Research, Vol.20 No.4, pp.416-434.

Hair, J. H., Jr., Black, W. C., Babin, B. J. and Tatham, R. L. (2005), Multivariate data Analysis, Prentice Hall, Upper Saddle River, NJ.

Hall, C.M., Sharples, L., Mitchell, R., Mavionis, N. and Cambourne, B. (2003), Food tourism around the world: Development, management and markets, Butterworth-Heinemann: Oxford.

Henderson, J. C. (2009), "Food tourism reviewed", British Food Journal. Vol. 111 No. 4, pp. 317-332.

Hjalager, A. M. (2004), "What do tourists eat and why? Towards a sociology of gastronomy and tourism, Tourism", Vol.52 No. 2, pp. 195-201 .

Horng, J. and Tsai, C. (2012), "Culinary tourism strategic development: an Asia-Pacific Perspective”, International Journal of Tourism Research, Vol. 14 No. 1, pp. 40-55.

Hu, Z.S. (2006). Chinese culinary culture. Beijing, China: Current Affairs Press 
Huang, R. (2009), "The role of food in promoting Chinese regions on the web", Int. J. Tourism Policy, Vol. 2 No.4, pp.289-305.

Ignatov, E. and Smith, S. (2006), "Segmenting Canadian culinary tourists", Current Issues in Tourism, Vol. 9 No.3, pp.235- 254.

Kim, Y. G., Eves, A. and Scarles, C. (2009), "Building a model of local food consumption on trips and holidays: A grounded theory approach", International Journal of Hospitality Management, Vol. 28, pp.423-431.

Kim, Y.G., Eves, A. and Scarles, C. (2013), "Empirical verification of a conceptual model of local food consumption at a tourist destination", International Journal of Hospitality Management, Vol. 33 No.1, pp.484-489.

Kim, Y. H., Goh, B.K. and Yuan, J.X. (2010), "Development of a Multi-Dimensional Scale for Measuring Food Tourist Motivations", Journal of Quality Assurance in Hospitality \& Tourism, Vol.11 No.1, pp.56-71.

Long, L. M. (2004), Culinary tourism, The University Press of Kentucky: Lexington.

López-Guzmán, T., Di-Clemente, E. and Hernández-Mogollón, J.M. (2014), “Culinary tourists in the Spanish region of Extremadura, Spain”, Wine Economics and Policy, Vol.3 No.1, pp.1018.

López-Guzmán, T., Lotero, C.P., Gálvez, J.C. and Rivera,I.R. (2017), "Gastronomic festivals: attitude, motivation and satisfaction of the tourist", British Food Journal, Vol. 119 No. 2, pp. $267-283$.

Mason, M. and Paggiaro, A. (2012), "Investigating the role of festivalscape in culinary tourism: The case of food and wine events", Tourism Management, Vol. 33, 1329-1336.

McKercher, B.F.,Okumus, F. and Okumus, B. (2008), "Food tourism as a viable market segment: It's all how you cook the numbers!”, Journal of Travel \&Tourism Marketing, Vol. 25 No. 2, pp.137-148.

Mitchell, R. and Hall, C. (2003), "Consuming tourists: Food tourism consumer behaviour", in C. Hall, L. Sharples, R. Mitchell, N. Macionis and B. Cambourne (Eds.), Food tourism around the world: Development, management and markets, Butter-worth-Heinemann, Oxford, pp. 6484.

National Bureau of Statistics of China. (2011), The national bureau of statistics of People's Republic of China on major figures of the 2010 population census, from: http://www.stats.gov.cn/english/ (Accessed October 3, 2015)

Nield, K., Kozak, M. and LeGrys, G. (2000), "The role of food service in tourist satisfaction", International Journal of Hospitality Management, Vol.19 No.4, pp.375-384. 
Qi, C.H., Sun, S.R. and Mei, Q. (2009), Discussion on food and tourism, China Business, Vol. 22, pp.67-69.

Quan, S. and Wang, N. (2004), "Towards a structural model of the tourist experience:

An illustration from food experiences in tourism", Tourism Management, Vol.25 No.3, pp. 297-305.

Pearce, P. L., Wu, M.Y. and Osmond, A. (2013), "Puzzles in understanding Chinese tourist behaviour; towards a triple-C gaze", Tourism Recreation Research, Vol. 38 No.2, pp.145-157.

Robinson, R.N.S. and Getz, D. (2014), "Profiling potential food tourists: and Australian study", British Food Journal, Vol.116 No. 4, pp. 690-706.

Sánchez-Cañizares, S.M. and López-Guzmán,T. (2012), "Gastronomy as a tourism resource: Profile of the culinary tourist", Current Issues in Tourism, Vol.15 No.3, pp.229-245.

Sims, R. (2009), "Food, place and authenticity: local food and the sustainable tourism Experience", Journal of Sustainable Tourism, Vol.17 No.3, pp. 321-336.

Simmons, F. J. (1991). Food in China: a cultural and historical Inquiry. CRC Press, New York.

Smith, S. and Costello, C. (2009), "Segmenting visitors to a culinary event: Motivations, travel behaviour, and expenditures", Journal of Hospitality Marketing \& Management, Vol.18 No.1, pp. 44-67.

Sparks, B. (2007), "Planning a wine tourism vacation? Factors that help to predict tourist behavioural intentions", Tourism Management, Vol. 28 No.5, pp.1180-1192.

Sun, Y. and Xie, Z.T. (2014), "Research on the development of new tourism forms in China", Global Humanities and Geography, Vol. 22, pp. 56-58.

Tikkanen, I. (2007), Maslow's hierarchy and food tourism in Finland: five cases, British Food Journal, Vol.109 No.9, pp.721-734.

Tourism and Recreation Research Unit. (1983), Recreation Site Survey Manual - Methods and Techniques for Conducting Visitor Surveys, E. \& F. N. Spon, London.

Wang, X. M. (2011), "The development of culinary tourism in Zhejiang”, Journal of Sichuan Higher Institute of Cuisine, Vol.16 No.4, pp. 67-69.

Wu, X. D. (2010), "Development strategies of Chinese food in leisure and economic tourism perspective", China Business \& Trade, Vol.19 No.19, pp.141-142.

Yu, L., Hong, J. and Xiong, L. F. (2009), "Studies on catering culture tourism resources development in Yibin”, Resource Development \& Market, Vol.25 No.1, pp.80-83. 


\begin{tabular}{|c|c|c|c|c|}
\hline Food-related motivation & $\begin{array}{l}\text { Apathetic } \\
\text { food tourist } \\
n=156\end{array}$ & $\begin{array}{l}\text { Accidental } \\
\text { food tourists } \\
n=579\end{array}$ & $\begin{array}{l}\text { Committed } \\
\text { food tourists } \\
n=618\end{array}$ & $\begin{array}{l}\text { ANOVA } \\
\text { F value }\end{array}$ \\
\hline $\begin{array}{l}\text { Food plays an important } \\
\text { role in my destination } \\
\text { choice. }\end{array}$ & $2.95^{\star *}$ & $4.74^{* *}$ & $6.14^{* *}$ & $686.49^{* *}$ \\
\hline $\begin{array}{l}\text { Prior to my trip, I planned } \\
\text { food choices to experience } \\
\text { local culture. }\end{array}$ & $3.17^{* *}$ & $4.92^{* *}$ & $6.27^{* *}$ & $760.29^{* *}$ \\
\hline $\begin{array}{l}\text { I might decide on } \\
\text { destinations to visit only } \\
\text { base on the foods I want to } \\
\text { experience }\end{array}$ & $2.40^{* *}$ & $3.98^{* *}$ & $5.61^{* *}$ & $602.92^{* *}$ \\
\hline $\begin{array}{l}\text { I usually do some research } \\
\text { about the local food or } \\
\text { restaurants prior to my trip. }\end{array}$ & $2.78^{* *}$ & $4.41^{* *}$ & $5.98^{\star *}$ & $676.99^{* *}$ \\
\hline $\begin{array}{l}\text { Prior to my trip, one of the } \\
\text { things I anticipate is eating } \\
\text { the food there. }\end{array}$ & $2.53^{* *}$ & $4.55^{\star *}$ & $6.29^{* *}$ & $1092.65^{\star *}$ \\
\hline $\begin{array}{l}\text { I like trying different styles } \\
\text { or types of food during } \\
\text { travel }\end{array}$ & $3.90^{* *}$ & $5.33^{* *}$ & $6.46^{* *}$ & $451.83^{\star *}$ \\
\hline Overall Mean & $2.96^{* *}$ & $4.66^{* *}$ & $6.13^{\star *}$ & $2783.54^{\star *}$ \\
\hline \multicolumn{5}{|c|}{$\begin{array}{l}\text { Note: } \\
\text { Mean values of the statements are significantly different with post-hoc Scheffe } \\
\text { analysis at } p<0.001 \text { of the three clusters. } \\
{ }^{\star} p<0.01 ;{ }^{\star \star} p<0.001\end{array}$} \\
\hline
\end{tabular}


Table 2 Differences in tourists' food experience between genders

\begin{tabular}{llllll}
\hline & Gender & $\mathrm{N}$ & Mean & $\begin{array}{l}\text { Std. } \\
\text { Deviation }\end{array}$ & t value \\
$\begin{array}{l}\text { Food-related } \\
\text { motivation }\end{array}$ & Male & 637 & 19.51 & 4.98 & $-4.577^{* *}$ \\
& Female & 716 & 20.75 & 4.90 & \\
$\begin{array}{l}\text { Food } \\
\text { involvement }\end{array}$ & Male & 637 & 40.81 & 8.82 & $-6.315^{* *}$ \\
& Female & 716 & 43.68 & 7.79 & \\
$\begin{array}{l}\text { Food } \\
\text { satisfaction }\end{array}$ & Male & 637 & 19.78 & 4.61 & $-2.656^{* *}$ \\
$\begin{array}{l}\text { Food-related } \\
\text { behavioural } \\
\text { intentions }\end{array}$ & Female & 716 & 20.43 & 4.43 & \\
\hline${ }^{*} \mathrm{p}<0.01 ;{ }^{* *} \mathrm{p}<0.001$ & 637 & 19.87 & 4.04 & $-4.899^{* *}$ \\
& Female & 716 & 20.91 & 3.73 & \\
\hline
\end{tabular}

